\title{
Çeltik (Orzya sativa L.) Genotiplerinin Trakya Koşullarının Farklı Lokasyonlarında Adaptasyonu ve Bazı Karakterler Yönünden Stabilite Analizleri
}

\author{
*Halil SÜREK Turhan KAHRAMAN Rasim ÜNAN \\ Trakya Tarımsal Araştırma Enstitüsü, Edirne \\ *Sorumlu Yazar e-posta: surekhalil55@gmail.com
}

\begin{abstract}
Öz
Bu araştırmanın amacı, Trakya koşullarının farklı lokasyonlarında, çeltik genotiplerinin performansını belirlemek ve bazı karakterler yönünden stabilitelerini tespit etmektir. Çalışmada, 14 çeltik genotipi kullanılmıştır. Bu genotipler, 2013 ve 2014 yıllarında, Trakya bölgesinde bulunan, Edirne Merkez ve İpsala ilçeleri ile Tekirdağ'ın Hayrabolu ilçesinde tesadüf blokları deneme deseninde 3 tekerrürlü olarak yürütülmüştür. Araştırmada, genotiplerin çeltik tane verimi, çeltik ve pirinç 1000 tane ağırlıkları ile kırıklı ve kırıksız pirinç randımanı değerleri incelenmiştir. Bu özellikler bakımından çeşitler arasında önemli farkılıklar tespit edilmiştir. Aynı zamanda, bu karakterler yönünden çevre ve genotipxçevre interaksiyonları önemli bulunmuştur. Çeltik tane verimi yönünden TR-2296, TR-2241, TR-2337 ve TR-2340, kırıksız pirinç randımanı yönünden TR-2305 ve çeltik 1000 tane ağırı̆̆ı bakımından ise TR-2271, TR-2340 ve TR-2302 genotipler en stabil olarak belirlenmiştir. Diğer taraftan bu karakterler için genotiplerin bazıları iyi, bazıları da kötü çevre koşullarında daha iyi performans göstermişlerdir. İncelenen bu üç karakter bakımından TR-2340'ın en stabil genotip olduğu görülmüştür.
\end{abstract}

Anahtar Kelimeler: Çeltik (Oryza sativa L.), çeltik genotipi, çeşit çevre intraksiyonu, stabilite

\section{The Adaptation of Some Rice Genotypes to Thrace Conditions and Their Stability Parameters for Some Traits in Turkey}

\begin{abstract}
The objectives of this study were to determine the performance of some rice genotypes and their stability parameters for some traits in the different locations under Thrace part of Turkey. Fourteen rice genotypes were used in this research. These genotypes were tested in the randomized complete block design with three replications in the three locations, such as the centre and İpsala towns of Edirne and Hayrabolu town of Tekirdağ provinces in Thrace region of Turkey. The genotypes were examined in terms of rough rice yield, 1000 grain weight of paddy and milled grains, total milled rice percentage and head rice percentage. The statically important differences were determined among the genotypes for these traits. At the same time, the results of combined analysis of variance (ANOVA) revealed GenotypexEnvironment interactions for the examined characters of different genotypes. According to the stability parameter analysis, the genotypes, TR-2296, TR-2241, TR-2337, and TR-2340 for rough rice yield, TR-2305 for head rice yield percentage, TR2271, TR-2340, and TR-2302 for 1000 grain weight were suitable for all environments, respectively. Whereas, some genotypes had better performance in better environments and some of them in poor environments. TR-2340 was the most suitable genotype for all environments in terms of the examined traits.
\end{abstract}

Keywords: Rice (Oryza sativa L.), rice genotype, genotypexenvironment interaction, stability

\section{Giriş}

eltik (Oryza sativa L.) dünyada insan beslenmesinde kullanılan ve gıda güvenliği açısından önemli bir üründür. Çeltik verimi, toplam üretim ve piyasada fiyatların stabilitesi açısından önemlidir. Bu nedenle, ıslah edilen çeşitler, tescilinden uzun bir süre veya farklı lokasyosyonlarda stabil bir verim vermesi istenir. Bu sebepten, tescil edilmeden önce, çeşitler farklı lokasyonlarda denenmek zorundadırlar. Çünkü bir çeşit tescil edildikten sonra, çiftçiler tarafından farklı lokasyonlarda yetiştirilecektir. Çoklu lokasyon deneme 
sonuçları, çeşitlerin farklı lokasyonlardaki verim potansiyeli ile lokasyonlar arasındaki farkı yansıtmaktadır. $\mathrm{Bu}$ durum çeşitxçevre interaksiyonu sonucunu ortaya çıkarmaktadır. Çeşitxçevre interaksiyonu, ıslahçıların, farklı çevre koşullarında, yüksek seviyede stabil bir verim elde edilebilecek çeşitlerin geliştirilmesini zorlaştırmaktadır. Bu nedenle, bir çeşidin tescil edilmeden önce, stabil bir verim vermesi arzu edilen bir özelliktir.

Stabilite, farklı stres koşullarında ortaya çıkan kompleks bir yapıya sahiptir. Stabilite ile genotip ve çevre interaksiyonunun ortaya konabilmesi için, ıslahçılar tarafından çeşitler farklı lokasyonlarda denenmelidir. Verim stabilitesi, çevre faktörleri, yetiştirme tekniği uygulamaları ve hastalık-zararlı baskısı gibi faktörler tarafından etkilenmektedir ( $\mathrm{Hu}$ and Buyanovsky 2003). Geliştirilen bir genotipin yıldan yıla farklı derecede stabilite göstermesi, ıslahçılar için önemli bir sorun yaratır. Bu nedenle, farklı çevre koşullarındaki genetik performansı ölçmede kullanılan bazı metotlar geliştirilmiştir. Bunun için çoklu lokasyonlarda birçok yıl denemeler yürütülmektedir (Luthra et al. 1974). Bir karakterin performans seviyesi, genotipin yetiştirildiği çevredeki, genetikxçevre interaksiyonun sonucu olarak ortaya çıkmaktadır (Allard and Bradshaw, 1964). Genotip x çevre interaksiyonu önemli ölçüde genotipin, fenotipik yapısını etkilemektedir. Bunun sonucu, çeşitlerin seçiminde bitki ıslahçılarına yardım etmek için çeşitlerin farklı lokasyonlardaki performansını belirlemek amacıyla, stabilite analizi gereklidir. Bir çeşidin, farklı lokasyonlarda stabil bir durum göstermemesi, çeşitxçevre interaksiyonunun sonucudur (Jusuf et al. 2008). Tane verimi; genotip, çevre ve yetiştirme tekniği ile bunlar arasındaki interaksiyona bağlıdır (Messina et al. 2009). Aynı yetiştirme tekniği koşullarında, tane veriminde ortaya çıkan varyasyonun sebebi, genotip ve çevrenin etkisi şeklinde açıklanabilir (Dingkuhn et al. 2006).

Blanche et al. (2009) çeltik verimi ve kırıksız pirinç randımanı için bazı çeltik çeşitlerinin stabil bir performans gösterdiğini tespit etmişlerdir. Padmavathi et al. (2013) kırıksız pirinç randımanı için çeşitxçevre inteaksiyonunun önemli olduğunu bildirmişlerdir. Hindistan'da Bose et al. (2012) çeltik verimi için çeşitxçevre interaksiyonun önemli olduğunu, bazı çeşitler tüm çevre koşullarında stabil performans gösterirken, bazılarının iyi ve bazılarının da kötü çevre koşullarında daha iyi performans gösterdiğini belirlemişlerdir. Upreti et al. (2007) Nepal'de, yaptıkları bir çalışmada çeşit, çevre ve çeşitxçevre interaksiyonunun önemli olduğunu ve bazı çeşitlerin tüm çevre koşullarında stabil bir verim verdiğini, bazılarının ise iyi çevre koşullarında daha iyi sonuç verdiğini tespit etmişlerdir. Shantakumar et al. (1997) Hindistan'da ve Palanog et al. (2014) Filipinlerde benzer sonuçları elde etmişlerdir. Diğer taraftan, Tariku et al. (2013) Etyopya'da tane verimi bakımından genotip, çevre ve genotipxçevre interasiyonun önemli olduğunu, ancak, hiçbir çeşidin tüm çevre koşullarında, stabil verime sahip olmadığını, bazı çeşitlerin ise iyi çevre koşullarında daha iyi performans gösterdiklerini bildirmişlerdir.

Ünay ve ark. (1990) yılında Edirne'nin (Merkez) ilçe, Uzunköprü, Meriç ve İpsala ilçelerini kapsayan çevre koşullarında yaptıkları bir çalışmada, bin tane ağırlığı için çeşitxçevre interaksiyonunun önemli, tane verimi için ise önemli olmadığını belirlemişlerdir. Stabilite analizi sonucunda, bir çeşit adayı hattın incelenen karakterler bakımından, tüm çevre koşullarına iyi uyum sağladığını tespit etmişlerdir. Diğer taraftan Şahin ve ark. (2011) Edirne ve Samsun illeri lokasyonlarında yaptıkları çalışmada çeşit çevre interaksiyonun önemli olduğunu ve stabilite parametrelerine göre Osmancık-97 ve Demir çeşitlerinin en stabil çeşit olduğunu, ortaya koymuşlardır.

Trakya bölgesinde ülkemiz çeltik üretiminin yarıya yakınını üretilmektedir. Edirne merkez ve ipsala ilçeleri ile Tekirdağ'ın Hayrabolu ilçeleri, bu illerin önemli çeltik üreticisi ilçeleridir ve coğrafi konumları itibarıyla, farklılıklar göstermektedir. Bu araştırmada; bu lokasyonlarda çeltik genotiplerinin performenslarını belirlemek ve bazı karakterler yönünden stabilitelerini tespit etmek amaçlanmıştır.

\section{Materyal ve Yöntem}

Araştırmada, Trakya Tarımsal Araştırma Enstitüsünde geliştirilmiş 11 Islah hattı (TR2296, TR-2302, TR-2305, TR-2313, TR-2337, TR-2340, TR-2343, TR-2241, TR-2259, TR2271 ve TR-2275) ile Halilbey, Osmancık-97 ve Edirne ticari çeşitleri olmak üzere toplam 14 genotip çalışmada yer almıştır.

Araştırma ile ilgili denemeler 2013 ve 2014 yıllarında Edirne'nin Merkez ve İpsala ilçeleri ile Tekirdağ'ın Hayrabolu ilçelerinde yürütülmüştür. 
Sürek et al. "The Adaptation of Some Rice Genotypes to Thrace Conditions and Their Stability Parameters for Some Traits in Turkey"

Table 1. Araştırmanın yürütüldüğü lokasyonların uzun yıllar iklim verileri ortalaması (1964-2014)

Table 1. Long term averages of climate data of trial area between 1964-2014

\begin{tabular}{|c|c|c|c|c|c|c|c|}
\hline İklim özelliği & Lokasyon & Nisan & Mayıs & Haziran & Temmuz & Ağustos & Eylül \\
\hline \multirow{3}{*}{$\begin{array}{l}\text { En yüksek sıcaklıklar } \\
\text { ortalaması }{ }^{\circ} \mathrm{C}\end{array}$} & Edirne & 19.3 & 24.8 & 29.2 & 31.7 & 31.6 & 27.2 \\
\hline & Merkez & 10 & & & & 210 & \\
\hline & Havrabolu & $\begin{array}{l}10.4 \\
18.2\end{array}$ & 24.1 & 20.9 & 31.3 & 31.3 & 27.1 \\
\hline \multirow{4}{*}{$\begin{array}{l}\text { En düşük sıcaklıklar } \\
\text { ortalaması }{ }^{\circ} \mathrm{C}\end{array}$} & Fdirne & $7 ?$ & 110 & 15 & 172 & 171 & 120 \\
\hline & Merkez & & & & & & \\
\hline & İpsala & 7.8 & 12.0 & 15.9 & 17.8 & 17.4 & 13.8 \\
\hline & Hayrabolu & 6.9 & 11.0 & 14.4 & 16.1 & 15.6 & 12.8 \\
\hline \multirow[t]{3}{*}{ Ortalama sıcaklık ${ }^{\circ} \mathrm{C}$} & Edirne & 12.9 & 18.2 & 22.4 & 24.7 & 24.3 & 19.8 \\
\hline & Merkez & 128 & 170 & 224 & 246 & 242 & 20 \\
\hline & Hayrabolu & $\begin{array}{l}12.0 \\
12.1\end{array}$ & 17.2 & 21.0 & $\begin{array}{l}24.6 \\
23.2\end{array}$ & $\begin{array}{l}24.2 \\
22.4\end{array}$ & 19.1 \\
\hline \multirow{3}{*}{$\begin{array}{l}\text { Aylık ortalama } \\
\text { toplam yağış }(\mathrm{mm})\end{array}$} & Edirne & 47.1 & 52.6 & 43.8 & 33.0 & 23.5 & 39.2 \\
\hline & İpsala & 41.4 & 32.7 & 32.2 & 16.2 & 10.9 & 32.5 \\
\hline & Hayrabolu & 38.4 & 32.5 & 39.0 & 25.6 & 13.3 & 19.2 \\
\hline \multirow{3}{*}{$\begin{array}{l}\text { Aylık ortalama } \\
\text { yağışın gün sayısı }\end{array}$} & Edirne & 10.6 & 10.1 & 8.4 & 5.6 & 4.3 & 4.8 \\
\hline & İpsala & 8.3 & 7.4 & 5.9 & 3.2 & 2.4 & 3.9 \\
\hline & Hayrabolu & 5.7 & 4.9 & 4.9 & 2.4 & 2.0 & 2.3 \\
\hline \multirow{3}{*}{$\begin{array}{l}\text { Aylık ortalama nispi } \\
\text { rutubet }(\%)\end{array}$} & Edirne & 67.6 & 64.4 & 60.1 & 55.9 & 56.2 & 62.2 \\
\hline & İpsala & 74.1 & 70.6 & 66.0 & 62.7 & 63.4 & 68.6 \\
\hline & Hayrabolu & 72.3 & 69.3 & 66.2 & 63.3 & 64.8 & 69.7 \\
\hline
\end{tabular}

Bu lokasyonlardan Edirne Merkez ilçesi $41^{\circ} 40^{\prime}$ kuzey enlemi ile $26^{\circ} 34^{\prime}$ doğu boylamında ve $41 \mathrm{~m}$ rakımında, İpsala $40^{\circ} 55^{\prime}$ kuzey enlemi ile $26^{\circ} 22^{\prime}$ doğu boylamında ve $10 \mathrm{~m}$ rakımında ve Hayrabolu ise $41^{\circ} 13^{\prime}$ kuzey enlemi ile $27^{\circ} 5^{\prime}$ doğu boylamında ve $108 \mathrm{~m}$ rakımında bulunmaktadır.

Deneme lokasyonları ile ilgili uzun yıllar iklim verileri incelendiğinde; yüksek sıcaklık değerleri bakımından, lokasyonlar arasında çeltik tarımına olumsuz etki yapacak bir durum yoktur.

En düşük sıcaklıklar ve ortalama sıcaklıklar göz önünde bulundurulduğunda, İpsala lokaskonu daha avantajlı durumda olduğu görülmektedir. Diğer taraftan, en düşük sıcaklıklar ortalaması bakımından, Hayrabolu lokasyonu çeltik için çok uygun bir lokasyon olarak görülmemektedir. Edirne merkez ilçe lokasyonu en yüksek aylık yağış miktarı ve yağışlı gün sayısına sahiptir. İpsala lokasyonunda en yüksek nispi rutubet değerleri gözlenmektedir (Çizelge 1).

Araştırmada yürütülen denemeler, Edirne Merkez, İpsala ve Hayrabolu lokasyonlarında tesadüf blokları deneme deseninde 3 tekerrürlü olarak yürütülmüştür. Verim denemeleri için ekim, ön çimlendirme işlemi yapılmış tohumların su içerisine elle serpilmesi şeklinde,

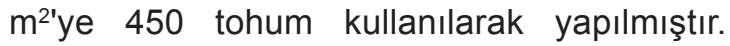

Ekimde, parsel alanı $4 \times 5=20 \mathrm{~m}^{2}$, hasatta ise $3.5 \times 4.5=15.75 \mathrm{~m}^{2}$ olarak dikkate alınmıştır. Dekara $\mathrm{N}_{18} \mathrm{P}_{5} \mathrm{~kg}$ hesabı üzerinden gübre uygulaması yapılmıştır.

Materyalin değerlendirilmesinde, çeltik tane verimi, çeltik ve pirinç 1000 tane ağırlığı, toplam ve kırıksız pirinç randımanı gibi özellikler bakımından değerlendirmeler yapılmıştır (IRRI 1996). Değerlendirmede varyans analizi ile regrasyon katsayısı (bi) ve regrasyondan sapma kareler ortalaması (Sd2) gibi stabilite parametrelerinin belirlenmesi (Finlay and Wilkinson 1963; Eberhart and Russull 1996)'a göre yapılmıştır.

\section{Bulgular ve Tartışma}

Yapılan varyans analizi sonuçları, incelenen karakterler bakımından genotipler ve çevreler arasında istatistiki anlamda önemli farklılıkların olduğu bulunmuştur (Çizelge 2). İncelenen karakterlerin tamamı için çeşitxçevre interaksiyonu önemli bulunmuştur. Lokasyonların birleştirilmiş analizine göre, çeşitlerin çeltik tane verimi (610.2-735.7 $\mathrm{kg} / \mathrm{da}$ ), çeltik bin tane ağırlığı (29.4-38.9 g), pirinç 1000 tane ağırlığı (22.5-29.4 g), toplam pirinç randımanı (\%70.6-74.1) ve kırıksız pirinç randımanı ise (\%60.8-69.1) arasında değişim göstermiştir. Çeltik tane veriminde, bazı araştırıcılar tarafından benzer sonuçlar elde 
edilmiştir (Upreti et al. 2007; Şahin ve ark. 2011; Bose et al. 2012; Tariku et al. 2013;). Diğer taraftan, Ünay ve ark. (1990) Edirne ilinde 4 loakasyonda iki yıl süre ile yaptıkları bir çalışmada, çeltik tane verimi için çeşitxçevre interaksiyonunun önemli olmadığını tespit etmişlerdir. Bunun yanında, Padmavathi et al. (2013) kırıksız pirinç randımanı, Ünay ve ark. (1990) çeltik 1000 tane ağırlığı yönünden çeşitxçevre interaksiyonun önemli olduğunu bildirmişlerdir.

Stabilite parametresi olarak kullanılan en uygun metotlardan biri regrasyon katsayısıdır (Finlay and Wilkinson 1963; Eberhert and Russell 1966). Regresyon katsayısı 1'e ne kadar yakın ise genotipin stabilitesi o kadar yüksektir. Stabilite parametresi olarak, regresyondan sapma da kullanılmış ve regresyondan sapması sıfıra yakın olan ve verim ortalaması genel ortalamadan yüksek genotipler stabil olarak kabul edilmektedir (Eberhart and Russell, 1966).

Bu çalışmada, çeltik verimi yanında, çeltik ve pirinç 1000 tane ağırlığı ile toplam ve kırıksız pirinç randımanı gibi özelliklerde incelenmiştir. Bu özelliklerden çeltik tane verimi ve kırıksız pirinç randımanı gibi özellikler çiftçilerin birim alandaki geliri arttırmada çok önem taşımaktadır. Bu nedenle, stabilite parametreleri yönünden yapılan değerlendirmede, yalnız çeltik tane verimi ve kırıksız pirinç randımanı üzerinde durulmuştur. Genotiplerin stabilite parametreleri incelendiğinde (Çizelge 3 ve Şekil 1) istatistiki olarak hesaplanan ortalama verimin üstünde verim değeri ve 1'e yakın regresyon katsayısı (bi) ve düşük regresyondan sapma kareler ortalamasına sahip (Sd2), TR-2296, TR2241, TR-2337 ve TR-2340 genotipleri tüm çevre koşullarına uyum sağlayarak, stabil çeltik tane verimi vermişlerdir. Diğer taraftan, ortalama verimin üstünde çeltik verimi veren 1 'in üzerinde regresyon katsayısı ve yüksek Sd2 değerine sahip, Halilbey çeşidi, iyi çevre koşullarında daha iyi sonuç vermiştir. Bunun yanında, 1 'in altında regresyon katsayısına sahip olan Osmancık-97, TR-2343, TR-2559 ve TR-2271 genotipleri kötü çevre koşullarında, çeltik tane verimi yönünden daha iyi performans göstermişlerdir. Padmathi et al. (2013); Bose et al. (2012) ve Upreti et al. (2007) yaptıkları çalışmalarda, çeltik tane verimi için çeşitlerin stabiliteleri açısından, benzer sonuçları elde ederken, Tariku et al. (2013) inceledikleri karakterler bakımından hiçbir çeşidin, tüm çevre koşullarına uyum sağlamadığını bildirmişlerdir. Şahin ve ark. (2011) Osmancık-97 çeşidinin, çeltik tane verimi açısından stabil bir çeşit olduğunu tespit etmişler, ancak, bu çalışmada, Osmancık-97 çeşidi kötü çevre koşullarında, çeltik tane verimi bakımından daha iyi performans göstermiştir. Kırıksız pirinç randımanı için stabilite parametreleri bakımından genotipler incelendiğinde; 1'e yakın regresyon katsayısı (bi), düşük regrasyondan sapma kareler ortalaması (Sd2) değerlerine ve genel ortalamansın üzerinde kırıksız pirinç randımanına sahip TR-2305 isimli genotip, tüm çevre koşullarında stabil bir kırıksız pirinç randımanı sonucu verdiği tespit edilmiştir (Çizelge 3 ve Şekil-2). Diğer taraftan, ortalamanın üzerinde kırıksız pirinç randımanı ve 1 'in üzerinde bi değeri sonucu veren Edirne çeşidi, iyi çevre koşullarında ve 1 'in altında bi değeri sonucu veren Osmancık-97, TR-2296, Halilbey, TR-2340, TR-2343 ve TR-2275 genotipleri, kötü çevre koşullarında daha iyi kırıksız pirinç randımanı değerlerine sahip olmuşlardır. Blanche et al. (2009) kırıksız pirinç randımanı için benzer sonuçları tespit etmişlerdir.

Table 2. Çeltik çeşitlerinde incelenen özelliklere ilişkin çevreler üzerinden birleştirilmiş varyans analizi sonuçları

Table 2. Variance analysis results for parameters with data from all locations are combined for each rice genotype

\begin{tabular}{lllllll}
\hline \multirow{2}{*}{ Varyans kaynağı } & & \multicolumn{2}{l}{ Kareler Ortalaması } \\
\cline { 3 - 7 } & S.D. & Çeltik verimi & $\begin{array}{c}\text { Çeltik } 1000 \\
\text { tane ağırlığı }\end{array}$ & $\begin{array}{l}\text { Pirinç } 1000 \\
\text { tane ağırığı }\end{array}$ & $\begin{array}{c}\text { Toplam } \\
\text { pirinç } \\
\text { randımanı }\end{array}$ & $\begin{array}{c}\text { Kırıksız } \\
\text { pirinç } \\
\text { randımanı }\end{array}$ \\
\hline Tekerrür (çevre) & 12 & $8762.77^{* *}$ & $2.359^{* *}$ & $1.132^{* *}$ & $0.670^{*}$ & $6.987^{* *}$ \\
Genotip & 13 & $26514.342^{* *}$ & $39.283^{* *}$ & $66.159^{* *}$ & $22.919^{* *}$ & $114.196^{* *}$ \\
Çevre & 5 & $349508.818^{* *}$ & $255.613^{* *}$ & $58.662^{* *}$ & $12.107^{* *}$ & $861.483^{* *}$ \\
Genotip x Çevre & 65 & $5001.456^{* *}$ & $1.548^{* *}$ & $0.478^{* *}$ & $3.114^{* *}$ & $30.334^{* *}$ \\
Hata & 156 & 2631.087 & 0.795 & 0.212 & 0.319 & 2.856 \\
\hline
\end{tabular}

* 0.05 ve ** 0.01 düzeyinde önemli

Significant at * 0.05 and ** 0.01 levels. 
Sürek et al. "The Adaptation of Some Rice Genotypes to Thrace Conditions and Their Stability Parameters for Some Traits in Turkey"
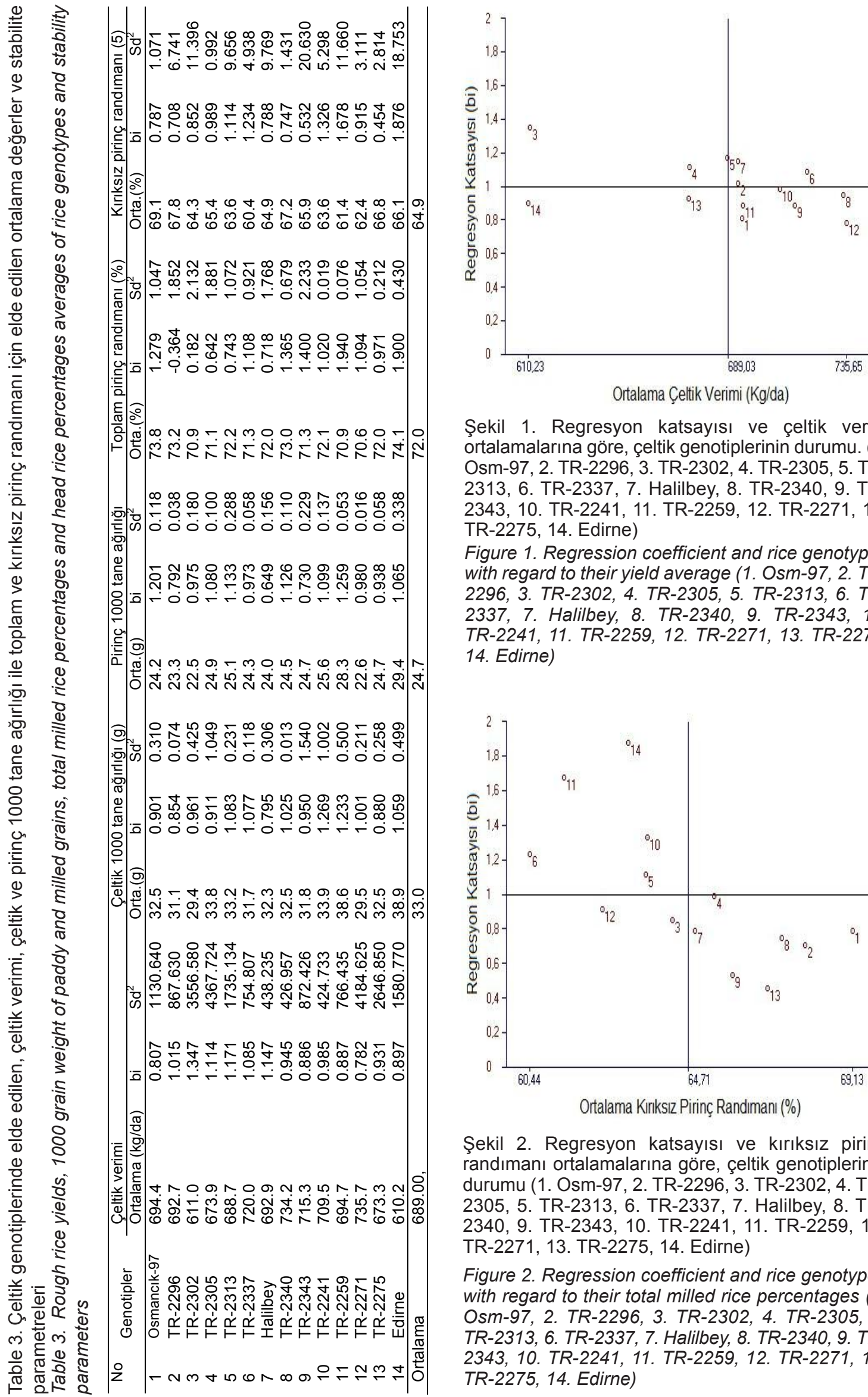

Şekil 1. Regresyon katsayısı ve çeltik verim ortalamalarına göre, çeltik genotiplerinin durumu. (1. Osm-97, 2. TR-2296, 3. TR-2302, 4. TR-2305, 5. TR2313, 6. TR-2337, 7. Halilbey, 8. TR-2340, 9. TR2343, 10. TR-2241, 11. TR-2259, 12. TR-2271, 13. TR-2275, 14. Edirne)

Figure 1. Regression coefficient and rice genotypes with regard to their yield average (1. Osm-97, 2. TR2296, 3. TR-2302, 4. TR-2305, 5. TR-2313, 6. TR2337, 7. Halilbey, 8. TR-2340, 9. TR-2343, 10. TR-2241, 11. TR-2259, 12. TR-2271, 13. TR-2275, 14. Edirne)

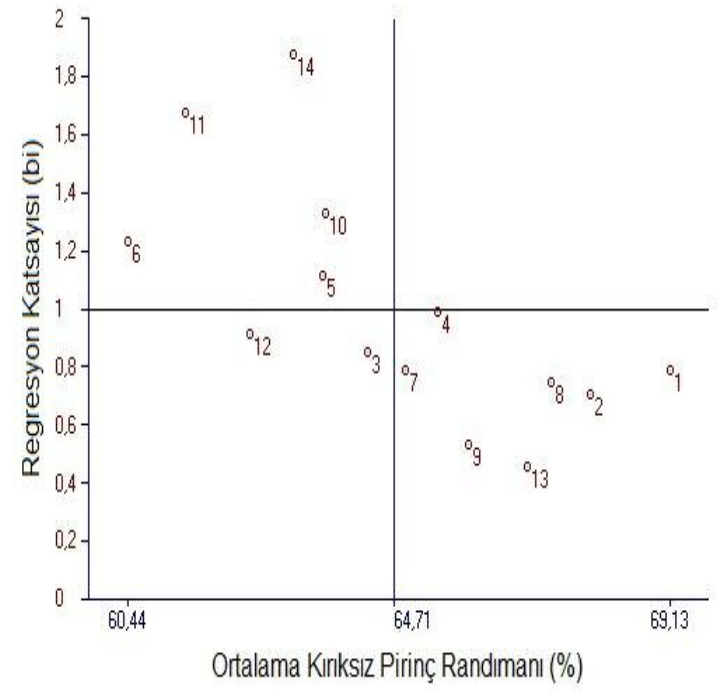

Şekil 2. Regresyon katsayısı ve kırıksız pirinç randımanı ortalamalarına göre, çeltik genotiplerinin durumu (1. Osm-97, 2. TR-2296, 3. TR-2302, 4. TR2305, 5. TR-2313, 6. TR-2337, 7. Halilbey, 8. TR2340, 9. TR-2343, 10. TR-2241, 11. TR-2259, 12. TR-2271, 13. TR-2275, 14. Edirne)

Figure 2. Regression coefficient and rice genotypes with regard to their total milled rice percentages (1. Osm-97, 2. TR-2296, 3. TR-2302, 4. TR-2305, 5. $T R-2313,6$. TR-2337, 7. Halilbey, 8. TR-2340, 9. TR2343, 10. TR-2241, 11. TR-2259, 12. TR-2271, 13. TR-2275, 14. Edirne) 


\section{Sonuç}

Trakya bölgesi, çok geniş bir alana sahip olmamasına rağmen, bu bölgeyi temsil eden üç lokasyonda yürütülen araştırma sonucuna göre, lokasyonlar arasında, incelenen karakterler yönünden çeşitxçevre interaksiyonu önemli çıkmıştır. Genotiplerin stabilite parametreleri göz önünde bulundurulduğunda; bazı genotipler, incelenen karakterler yönünden lokasyonlar arasında stabil birperformans gösterirken, bazıları iyi, bazıları da kötü çevre koşullarında daha iyi performans göstermişlerdir. İncelenen tüm karakterler yönünden TR-2340 genotipi en stabil olarak öne çıkmıştır.

\section{Kaynaklar}

Allard R.W. and Bradshaw A.D., 1964. Implication of genotype environment interactions in applied plant breeding. Crop Science, 4: 503-508

Blanche S.B., Utomo H.S., Wenefrida I. and Gerald O.G., 2009. Genotype x environment interactions of hybrid and varietal rice cultivars for grain yield and milling quality. Crop Sci., 49: 2011-2018.

Bose L.K., Nagaraju M. and Sing O.N., 2012 Genotype x Environment Interaction and Stability Analysis Of Lowland Rice Genotypes. Jour. Agric. Sci., 57(1): 1-8

Dingkuhn $\mathrm{M}$, Luquet $\mathrm{D}$, Kim $\mathrm{H}$, Tambour $\mathrm{L}$ and Clement-Vidal A, 2006. Ecomeristem, A model of morphogenesis and competition among sinks in rice. 2. simulating genotype responses to phosphorus deficiency. Functional Plant Biology, 33: 325-337

Eberhart S.A. and Russell W.A., 1966. Stability parameters for comparing varieties. Crop Science, 6: 36-40

Finlay W. and Wilkinson G.W., 1963. The analysis of adaptation in apalat breeding programme. J. Agri. Res., 14: 742-754.

Hu Q. and Buyanovsky G., 2003. Climate effects on corn yiled in Missouri. J. Applied Meteorology, 42: 1626-1635

Jusuf M., Rhayuningsih S.A., Wahyuni T.S. and Restuono J., 2008. Adaptasi dan stabilitas hasil klon harapan ubi jalar. Journal Penelitian Pertanian Tanaman Pangan, 27: 37-41
Luthra O.P., Singh R.K. and Kakar S.N., 1974. The stability of the twelve genotypes were evaluated. Theory and Applied Genetics, 45: 143-149

Messina C., Hammer G., Dong Z., Podlich D. and Cooper M., 2009. Modelling Crop Improvement in A GxExM Framwork via Gene-Trait-Phenptype Relationships. In: Crop physiology: Applications for Genetic Improvement and Agronomy, Eds., Sdras VO, Caldrini D, Elsevier, Netherlands, 235-265

Padmavathi P.V., Satyanarayana D.V., Ahmet L. and Chamundeswari N., 2013. Stability analysis of quality traits in rice hybrids. Oryza, 50(3): 199-204

Palanog A.D., Endino C.A., Ciocon I.W.G., Sta L.T. and Libetario E.W., 2014. Adaptability analysis of wewly-released rice varieties using GGE biplot analysis. Asia Life Sci., 23(2): 515-526

Shantakumar G., Kulkarni R.S. and Jagadeesha R.C., 1997. Stability Analysis in Rice (Oryza sativa L.) over Different Seasons for Yield and Its Components. Kamataka J. Agric. Sci., 10(1): $67-70$

Şahin M., Sürek H., Öner F. ve Üre T., 2011. Çeltikte Çeşit ya da Çeşit Adaylarının Performanslarının Belirlenmesi ve Stabilite Analizleri. IX. Tarla Bitkileri Kongresi, 12-15 Eylül 2011, Bursa, Cilt 1, 370-375

Tariku S., Lakew T., Bitew W. and Asfam M., 2013. Genotype by environment interaction and grain yield stability analysis of rice (Oryza sativa L.) genotype evaluated in north western Ethiopia. Net. J. Agric. Sci., 1(1): 1016

Upreti H.K., Bista Sudarshan B., Sah S.N. and Ohakal R., 2007. Genotype x environment interaction and stability analysis for grain yield of micledhill rice genotypes. Nepal Agric. Res., 8: 14-17

Ünay A., Turgut İ., Sürek H. ve Korkut Z.K., 1990. Çeltikte bazı özelliklerle ilgili stabilite analizi. Akdeniz Üni. Ziraat Fak. Derg., 3(1-2): 117124 